\title{
Dr Gerald W. Offer (1938-2019); an appreciation
}

\author{
Pauline Bennett $^{1}$ (D) Peter J. Knight ${ }^{2} \cdot$ K. W. Ranatunga ${ }^{3}$
}

Received: 3 October 2019 / Accepted: 15 October 2019 / Published online: 23 October 2019

(c) Springer Nature Switzerland AG 2019

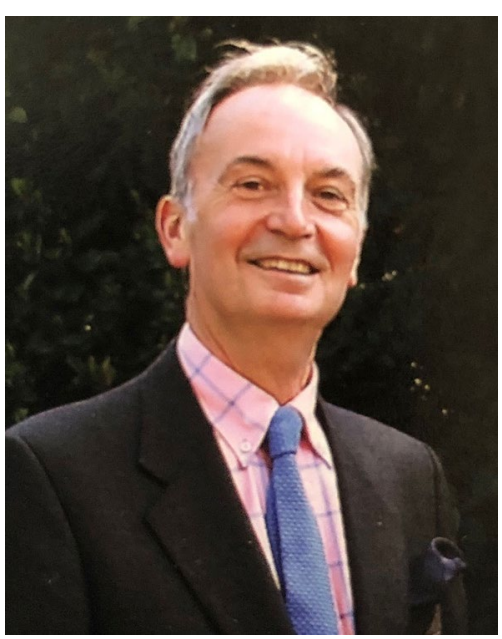

Gerald Offer was a meticulous, insightful and enthusiastic scientist, an inspiring teacher and a kind and generous colleague and friend. He trained as a biochemist and devoted his research career to understanding the function and structure of muscle, in particular the thick filament and its main constituent protein, myosin. He joined the muscle group at King's College London Biophysics Department under the leadership of Jean Hanson in the late 1960s. It was an exciting time with new developments in microscopy, particularly electron microscopy, and protein characterization leading to new insights into the organization and function of muscle. Among the many contributions Gerald made he will perhaps be best remembered for his work there in isolating and

Pauline Bennett

pauline.bennett@kcl.ac.uk

1 Randall Centre for Cell and Molecular Biophysics, King's College London, London, UK

2 Astbury Centre for Structural Molecular Biology and School of Molecular and Cellular Biology, University of Leeds, Leeds, UK

3 School of Physiology, Pharmacology \& Neurosciences, University of Bristol, Bristol, UK characterizing the thick filament accessory protein, myosin binding protein $\mathrm{C}$ (MyBP-C). While its function was unclear at the time, following more recent understanding of its role in hypertrophic cardiomyopathy and muscle disease, new research has been able to build on the careful groundwork carried out by Gerald and his colleagues. As 'father' of the field he was invited to give the plenary lecture at a recent MyBP-C meeting.

Gerald gained a first-class honours degree in Natural Sciences at King's College, Cambridge in 1960, winning prizes in each year. He went on to obtain his Ph. D. in the Biochemistry Department under the supervision of Dr Malcolm Dixon, F.R.S., an expert on enzyme purification and kinetics. Gerald's thesis on 'Structural and Enzymatic Properties of Myosin' was submitted in 1964. At that time myosin structure was poorly understood and the literature on its ATPase activity was full of contradictions, not least because many preparations were contaminated with actin. In his thesis he described experimental work aimed at determining the number of polypeptides in the myosin molecule and at explaining the many puzzling aspects of myosin ATPase activity. He also demonstrated his deep understanding of myosin in an incisive 150-page critical review of the existing literature that was part of his thesis but sadly was never published independently.

There followed a few years in the Biochemistry Department at University College, London as a postdoctoral fellow and assistant lecturer before taking up a position in 1967 as a Lecturer in Biochemistry in the Biophysics Department at Kings College, London. This move gave him an opportunity to work under the umbrella of Jean Hanson, F.R.S., the then Professor of Biology and an author of the sliding filament theory of muscle contraction. The head of the department was Professor Sir John Randall, F.R.S., who was also the director of the Medical Research Council's Biophysics Unit. Both Unit and Department were housed in a small but vibrant building on Drury Lane. Here there was a group with a long history of muscle structure studies, particularly using modern biophysical techniques such as X-ray diffraction, advanced light microscope techniques 
and electron microscopy. Jean Hanson with Jack Lowy had recently used electron microscopy to visualize the helical arrangement of actin sub-units in the muscle thin filament. Gerald with his biochemistry background was a valuable addition to the group.

Soon after he joined the Biophysics Department, the MRC unit was split into the Neurobiology Unit headed by Professor Maurice Wilkins, F.R.S. and Nobel Laureate, and the Muscle Biophysics Unit under the directorship of Jean Hanson. Unfortunately, this was a rather short-term arrangement since Jean suddenly and tragically died in 1973 and the two units were recombined. However, she established a thriving group with a very lively atmosphere which entertained a constant stream of international lecturers and visiting scientists, several of whom came to work with Gerald. At the 1978 Gordon Conference on Muscle more than 20 who attended were present or past members of staff, students or visiting scientists.

In his thesis Gerald had discussed the fact that myosin as was generally prepared was not pure. With Roger Starr, his career-long technical support, he set out to purify it and identify the contaminants. Using the newly developed SDS gel electrophoresis they identified at least ten bands of protein in a myosin preparation, which they labelled A-L. Several of the non-myosin bands they went on to characterize. In particular, proteins giving two of these bands, $\mathrm{C}$ and $\mathrm{H}$, now called MyBP-C and MyBP-H, bound strongly to myosin. These accessory proteins were purified and used to raise antibodies.

At the same time Jean Hanson was studying A-segments, the isolated bundles of thick filaments free of thin filaments, from muscle fibrils. She identified by electron microscopy extra material in 11 stripes in each half A-band. The $\mathrm{C}$ and $\mathrm{H}$ antibodies labelled some of these positions. Further meticulous work in the lab, was carried out particularly by Jean's graduate student Roger Craig, whose supervision was taken over by Gerald following Jean's death. This showed very precise positions for MyBP-C on 7-9 stripes in each half sarcomere. Although it was clear the MyBP-C could bind myosin rod and S1 and possibly actin as well, there was little idea how it could function. Since that time it has become clear that its role is complex. The $\mathrm{C}$-terminal part is bound to the thick filament; but the $\mathrm{N}$-terminal part can interact with either the actin filament or the myosin head, and it is now thought to exert control on the actomyosin interaction. Further, genetic analysis has revealed mutations in the protein which give rise to a high proportion of hypertrophic cardiomyopathies, indicative of its importance in muscle function.

Gerald also continued his analysis of myosin structure. With Arthur Elliot he refined the metal shadowing method for electron microscopy to characterize myosin molecule structure, its tail length and head shape. Using these results Gerald made his first foray into computer analysis to show that two heads from one myosin molecule could bind to two different thin filaments in the insect flight muscle lattice. This was supported by experimental data which he obtained with John Trinick. He was also interested in the filamentous organization of myosin and was involved in X-ray structural studies of paracrystalline arrays of the myosin tail with Naoto Yagi.

In 1977 Gerald became a reader but he still had a substantial teaching commitment. He was a most respected and popular lecturer. However, he decided that he wanted to reduce his teaching load and devote more time to research. In 1980 he took up the position of the Head of the Muscle Biology Division at the Agricultural and Food Research Council's Meat Research Institute (later The Institute of Food Research-Bristol Laboratory) near Bristol. Even here he kept his hand in as a lecturer, having an honorary position as a Reader at Bristol University. He continued to teach part of a biochemistry course there until the end of his career.

At the Meat Research Institute Gerald brought rigour to the research. He was very supportive of his staff, encouraging new approaches. He was a firm believer in the value of discussions over tea and the ideas that would be generated. At Drury Lane these discussions, ranging from gardening to the latest research paper, were a significant feature of the day. He attempted to instill this in the culture of the Meat Research Institute, even introducing tea time in his office. Personally, he was in charge of the myofibrillar structure section. A major aspect of his research was to understand the molecular reasons for post-mortem water-holding in meat and the role of salt and polyphosphates in meat processing. His biophysical understanding of muscle proteins and muscle structure allowed new analytical approaches to be brought to this project. With John Trinick he conducted experiments on myofibrils using the phase contrast light microscopy method that Jean Hanson had used in formulating the sliding filament theory of contraction, but in this case to demonstrate that lateral swelling and shrinking of the myofibrils could explain a host of previously puzzling properties of meat. Following a characteristically incisive evaluation of the literature on water holding, with Peter Knight he wrote a highly-regarded extensive review considered to be the classic in the field.

On moving to Bristol, Gerald purchased a house with a large garden in a small village nestling in the Mendip Hills. He spent many hours designing and building and planting what has become a most beautiful and restful haven. He was always happy to show it off. He and his long-term partner, Clive, whom he met as an undergraduate in Cambridge, were generous hosts. He regularly opened the garden for visitors to raise money for local charities. The garden became a parallel 'career' and he only reluctantly left it.

When the Institute of Food Research at Bristol closed in 1990, a small but strong group of muscle and collagen 
scientists under the leadership of Gerald and Allen Bailey and funded by the BBSRC transferred to the University of Bristol, Department of Clinical Veterinary Science. At this point he returned to a more molecular interest and started computer modelling of the structure of the myosin tail. He showed that kinks seen in the myosin tail corresponded to skip residues. He collaborated with both Richard Sessions on computer modelling of the $\alpha$-helical coiled coil of the myosin tail and, subsequently, with Dek Woolfson to model non-canonical coiled coils with a view to establishing the interactions between the myosin tails in the thick filament.

The Muscle and Collagen group came to an end when funding dried up in 1998 and Gerald became an Honorary Fellow in the School of Physiology, in Bristol University Medical School and, importantly for his modelling studies, maintained access to the university supercomputer system. The modelling work he did subsequently up until his death was, he felt, more central to understanding muscle contraction than anything he had done before.

In the late 1990s Gerald obtained funding that allowed him to make short visits to the USA over several years to work with Leepo Yu at NIH and Howard White at Eastern Virginia Medical School. This resulted in a productive collaboration identifying the enzymatic states of myosin and ATP analogues in relation to their structural conformation in relaxed and active muscle at different temperatures. Using enzyme kinetics and X-ray diffraction they concluded that only three conformational states of the myosin head were necessary to explain all the data. In particular they showed that the helical organization of the heads on the thick filament surface in relaxed muscle was associated with the 'closed' conformation of the head, and was favoured by the M.ADP.Pi nucleotide state which was present in higher proportions at physiological temperatures. Other nucleotide states favoured a disordered state.

Over the last 15 years or so in Bristol, Gerald entered upon a fruitful collaboration with his colleague, the physiologist KW Ranatunga, initially providing analytical modelling of his mechanical data. Subsequently, Gerald set out to formulate a computer model of muscle contraction. He argued that modelling of the crossbridge cycle would provide powerful insights into how muscle produced force and movement. Such a model should account for mechanical and energetic data as well as actomyosin kinetics and structural data. His initial analysis generated a cross-bridge model which showed that two, not one, tension generating steps were necessary to obtain a reasonable efficiency of muscle contraction. In a further development to understand why a change in temperature led to only a slow rise in tension compared to a small length change it was concluded that there were large endothermic changes in the pre-powerstroke states of myosin, M.ATP and M.ADP.P $\mathrm{P}_{\mathrm{i}}$, but the first tension generating state was only weakly endothermic.
Most recently, in a re-analysis of the work of Huxley and Simmons on force changes after small rapid length steps in muscle, they found that it was the first tensioning state that contributed to the initial changes in the observed force traces. Further developments of the model were planned. An investigation into the relationship between phosphate release from myosin and force generation had reached an advanced stage and a manuscript was in preparation at the time of Gerald's death.

Gerald continued going into his office at the University until ill health made it difficult for him to walk up the steep hill in Bristol. After this he continued his modelling from home with a view over his beloved garden.

Gerald's clarity of vision and understanding made him a wonderful colleague with whom to work. He was an open and generous collaborator; and many of his colleagues from the early days worked with him throughout his career. We could turn to him for advice at any time and we will miss him: A friend and mentor to live up to.

\section{References}

Bennett P, Craig R, Starr R, Offer G (1986) The ultrastructural location of C-protein, X-protein and $\mathrm{H}$-protein in rabbit muscle. J Muscle Res Cell Motil 7(6):550-567

Craig R, Offer G (1976a) Axial arrangement of crossbridges in thick filaments of vertebrate skeletal muscle. J Mol Biol 102(2):325-332

Craig R, Offer G (1976b) The location of C-protein in rabbit skeletal muscle. Proc R Soc Lond B 192(1109):451-461

Elliott A, Offer G (1978) Shape and flexibility of the myosin molecule. J Mol Biol 123(4):505-519

Moos C, Offer G, Starr R, Bennett P (1975) Interaction of C-protein with myosin, myosin rod and light meromyosin. J Mol Biol 97(1):1-9

Offer G (1990) Skip residues correlate with bends in the myosin tail. J Mol Biol 216(2):213-218

Offer G, Knight P (1988a) The structural basis of water holding in meat. Part 1: general principles of water uptake in meat processing. In: Lawrie RA (ed) Developments in meat science-4. Elsevier, Amsterdam, pp 63-171

Offer G, Knight P (1988b) The structural basis of water holding in meat. Part 2: drip losses. In: Lawrie RA (ed) Developments in meat science-4. Elsevier, Amsterdam, pp 173-243

Offer G, Knight P (1996) The structure of the head-tail junction of the myosin molecule. J Mol Biol 256(3):407-416

Offer G, Ranatunga KW (2013) A cross-bridge cycle with two tensiongenerating steps simulates skeletal muscle mechanics. Biophys $\mathbf{J}$ 105(4):928-940

Offer G, Ranatunga KW (2015) The endothermic ATP hydrolysis and crossbridge attachment steps drive the increase of force with temperature in isometric and shortening muscle. J Physiol 593(8):1997-2016

Offer G, Ranatunga KW (2016) Reinterpretation of the tension response of muscle to stretches and releases. Biophys J 111(9):2000-2010

Offer G, Sessions R (1995) Computer modelling of the alpha-helical coiled coil: packing of side-chains in the inner core. J Mol Biol 249(5):967-987 
Offer G, Moos C, Starr R (1973) A new protein of the thick filaments of vertebrate skeletal myofibrils. Extractions, purification and characterization. J Mol Biol 74(4):653-676

Offer G, Couch J, O'Brien E, Elliott A (1981) Arrangement of crossbridges in insect flight muscle in rigor. J Mol Biol 151(4):663-702

Offer G, Knight PJ, Burgess SA, Alamo L, Padron R (2000) A new model for the surface arrangement of myosin molecules in tarantula thick filaments. J Mol Biol 298(2):239-260

Offer G, Hicks MR, Woolfson DN (2002) Generalized Crick equations for modeling noncanonical coiled coils. J Struct Biol 137(1-2):41-53

Rome E, Offer G, Pepe FA (1973) X-ray diffraction of muscle labelled with antibody to C-protein. Nat New Biol 244(135):152-154

Starr R, Offer G (1971) Polypeptide chains of intermediate molecular weight in myosin preparations. FEBS Lett 15(1):40-44

Starr R, Offer G (1973) Polarity of the myosin molecule. J Mol Biol 81(1):17-31

Starr R, Offer G (1978) The interaction of C-protein with heavy meromyosin and subfragment-2. Biochem J 171(3):813-816

Starr R, Offer G (1983) H-protein and X-protein. Two new components of the thick filaments of vertebrate skeletal muscle. J Mol Biol 170(3):675-698
Trinick J, Offer G (1979) Cross-linking of actin filaments by heavy meromyosin. J Mol Biol 133(4):549-556

Xu S, Gu J, Rhodes T, Belknap B, Rosenbaum G, Offer G, White H, Yu LC (1999) The M.ADP.Pi state is required for helical order in the thick filaments of skeletal muscle. Biophys J 77(5):2665-2676

Xu S, White HD, Offer GW, Yu LC (2009) Stabilization of helical order in the thick filaments by blebbistatin: further evidence of coexisting multiple conformations of myosin. Biophys $\mathbf{J}$ 96(9):3673-3681

Yagi N, Offer GW (1981) X-ray diffraction and electron microscopy of a light meromyosin tactoid. J Mol Biol 151(3):467-490

Yu LC, Xu S, Gu J, White HD, Offer G (2003) Helical order in myosin filaments and evidence for one ligand inducing multiple myosin conformations. Adv Exp Med Biol 538:305-316

Publisher's Note Springer Nature remains neutral with regard to jurisdictional claims in published maps and institutional affiliations. 